\title{
Implications of albedo changes following afforestation on the benefits of forests as carbon sinks
}

\author{
M. U. F. Kirschbaum ${ }^{1}$, D. Whitehead ${ }^{2}$, S. M. Dean ${ }^{3}$, P. N. Beets ${ }^{4}$, J. D. Shepherd ${ }^{1}$, and A.-G. E. Ausseil ${ }^{1}$ \\ ${ }^{1}$ Landcare Research, Private Bag 11052, Palmerston North 4442, New Zealand \\ ${ }^{2}$ Landcare Research, P.O. Box 40, Lincoln 7640, New Zealand \\ ${ }^{3}$ NIWA, Private Bag 14-901, Wellington, New Zealand \\ ${ }^{4}$ Scion, Private Bag 3020, Rotorua, New Zealand
}

Received: 28 July 2011 - Published in Biogeosciences Discuss.: 24 August 2011

Revised: 5 December 2011 - Accepted: 5 December 2011 - Published: 15 December 2011

\begin{abstract}
Increased carbon storage with afforestation leads to a decrease in atmospheric carbon dioxide concentration and thus decreases radiative forcing and cools the Earth. However, afforestation also changes the reflective properties of the surface vegetation from more reflective pasture to relatively less reflective forest cover. This increase in radiation absorption by the forest constitutes an increase in radiative forcing, with a warming effect. The net effect of decreased albedo and carbon storage on radiative forcing depends on the relative magnitude of these two opposing processes.

We used data from an intensively studied site in New Zealand's Central North Island that has long-term, groundbased measurements of albedo over the full short-wave spectrum from a developing Pinus radiata forest. Data from this site were supplemented with satellite-derived albedo estimates from New Zealand pastures. The albedo of a wellestablished forest was measured as $13 \%$ and pasture albedo as $20 \%$. We used these data to calculate the direct radiative forcing effect of changing albedo as the forest grew.

We calculated the radiative forcing resulting from the removal of carbon from the atmosphere as a decrease in radiative forcing of $-104 \mathrm{GJ} \mathrm{tC}^{-1} \mathrm{yr}^{-1}$. We also showed that the observed change in albedo constituted a direct radiative forcing of $2759 \mathrm{GJ} \mathrm{ha}^{-1} \mathrm{yr}^{-1}$. Thus, following afforestation, $26.5 \mathrm{tC} \mathrm{ha}^{-1}$ needs to be stored in a growing forest to balance the increase in radiative forcing resulting from the observed albedo change. Measurements of tree biomass and albedo were used to estimate the net change in radiative forcing as the newly planted forest grew. Albedo and carbon-storage effects were of similar magnitude for the first
\end{abstract}

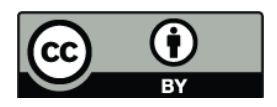

Correspondence to: M. U. F. Kirschbaum (kirschbaumm@landcareresearch.co.nz) four to five years after tree planting, but as the stand grew older, the carbon storage effect increasingly dominated. Averaged over the whole length of the rotation, the changes in albedo negated the benefits from increased carbon storage by $17-24 \%$.

\section{Introduction}

Establishing forests has long been regarded as a useful greenhouse mitigation option, as carbon is stored in trees rather than residing in the atmosphere where it would lead to global warming. However, the usefulness of that strategy was questioned through studies that explicitly considered the radiative forcing associated with changes in energy absorption vs reflection (albedo) at the surface (Brovkin et al., 1999; Betts, 2000; South et al., 2011). Those studies showed that, depending on the extent of albedo changes, incident radiation and carbon-storage potential at different locations, the benefit of tree plantings could be much diminished, or even become negative at sites with extended snow cover and poor tree-growth potential.

Betts (2000), in particular, concluded that in large parts of the temperate and boreal regions, the overall radiative forcing from a decrease in surface albedo by afforestation was equal in magnitude to the radiative forcing of increasing carbon sequestration. The albedo effect is more important at high latitudes because albedo differences between evergreen forest and pasture or cropland are greatly accentuated when snow covers the ground. In more temperate regions, like New Zealand, snow cover is less important, and albedo effects resulting from vegetation shifts are therefore likely to

Published by Copernicus Publications on behalf of the European Geosciences Union. 
be less important than in boreal regions with extended snow cover.

Bala et al. (2006) found that notional afforestation of the whole southern hemisphere at mid latitudes would result in a warming of $1.1^{\circ} \mathrm{C}$ due to the direct albedo effect. More specifically, Bala et al. (2007) found that forested regions in the tropical zone had significantly increased cloud cover, and that in this zone, the related change in cloud albedo was therefore sufficient to offset any changes in surface albedo for little effect on the overall radiation budget.

Similar studies were conducted by Zhang and Walsh (2007), Davin et al. (2007), Findell et al. (2007), Shi et al. (2007), Montenegro et al. (2009) and Pongratz et al. (2011), who confirmed the basic mechanisms relating albedo and global temperature changes, but differed in their numerical findings. These reported differences partly reflected differences in the scenarios used or regions covered by different workers, and partly reflect differences in assumptions or the completeness of factors that were included.

The fourth IPCC Assessment report (Forster et al., 2007) also summarised studies that had estimated the change in surface albedo with the expansion of agriculture since preindustrial times and concluded that land-use change is likely to have led to a radiative forcing of $-0.2 \pm 0.2 \mathrm{~W} \mathrm{~m}^{-2}$, leading to a global cooling of about $-0.1{ }^{\circ} \mathrm{C}$. Detailed studies also showed that within this broad global pattern, there is likely to be significant regional variation from 0 to $-5 \mathrm{~W} \mathrm{~m}^{-2}$ depending on the nature of the specific land use changes in different regions (Forster et al., 2007).

In quite a different study, Juang et al. (2007) combined modelling and observations and concluded that converting a grassland to pine or hardwood forest resulted in an overall cooling by about $1.5^{\circ} \mathrm{C}$, with a cooling effect of about $2.5^{\circ} \mathrm{C}$ due to greater latent heat (evaporative) and sensible heat exchange of forests offset by albedo-caused warming by about $0.8^{\circ} \mathrm{C}$. This study highlights the apparent contradiction between global and local effects. Forests can be cooler than neighbouring pasture, primarily because of the effects of evaporation, which cools the local environment. However, that local cooling is not relevant in the global context as evaporation simply transfers heat from the evaporating surface to the atmosphere. When the water vapour condenses as liquid in clouds or rain, the heat is returned to the atmosphere. On the global scale, the effects of evaporation and condensation cancel each other out with no net effect. Only effects on the radiative balance remain.

Conventionally, the net radiation, $Q_{\mathrm{n}}$, retained by a body, like the Earth, is given by the conservation equation:

$$
\begin{aligned}
Q_{\mathrm{n}} & =Q_{\mathrm{s}} \downarrow-Q_{\mathrm{s}} \uparrow+Q_{1} \downarrow-Q_{1} \uparrow \\
& =(1-\alpha) Q_{\mathrm{s}} \downarrow+Q_{1} \downarrow-Q_{1} \uparrow
\end{aligned}
$$

where the radiation components are $Q_{\mathrm{s}} \downarrow$ downward shortwave radiation, $Q_{\mathrm{s}} \uparrow$ upward reflected short-wave radiation, $Q_{1} \downarrow$ downward long-wave radiation and $Q_{1} \uparrow$ long-wave radiation emitted from the body and $\alpha$ is the albedo of the body, defined as the fraction of downward short-wave radiation that is reflected from the body (Landsberg and Gower, 1997).

Considering the Earth as a whole, incoming long-wave radiation and emission of short-wave radiation are negligible. Equation (1) can therefore be simplified and extended to give:

$Q_{\mathrm{s} \downarrow}-Q_{\mathrm{s}} \uparrow=(1-\alpha) Q_{\mathrm{s}} \downarrow=-Q_{1} \uparrow=f\left(T^{4}\right)$

where $T$ is temperature in Kelvin. This shows that, following the Stefan-Boltzmann law, the amount of long-wave radiation emitted from the Earth is a function of its temperature raised to the fourth power. Any decrease in albedo leads to increased energy absorption by the Earth. To regain energy equilibrium, outgoing long-wave radiation from the Earth must be increased to match the increased absorption of short-wave radiation, which can only be accomplished through an increase in temperature.

Values of albedo for darker coniferous forests lie in the range 8-15\% (Jarvis et al., 1976; Breuer et al., 2003; Hollinger et al., 2010), and values for more reflective pastures are usually 5-10\% higher (Breuer et al., 2003; Hollinger et al., 2010). A change in land use from pasture to conifer forest therefore results in a decrease in albedo, which has a direct effect on the surface radiation balance resulting from decreased reflected short-wave radiation (Betts, 2000). The increase in $Q_{\mathrm{n}}$ leads to an increase in radiative forcing, resulting in warming of the atmosphere. In addition, landuse change can have indirect effects on surface radiation balance through changes in evaporation that subsequently affect cloud formation, with effects on both short- and long-wave components (Bala et al., 2006, 2007).

Direct and indirect effects of changes in albedo associated with the conversion of pasture to forest are described in Fig. 1 (based on a figure from Findell et al., 2007). Storing carbon in vegetation reduces atmospheric $\mathrm{CO}_{2}$ and thereby allows more long-wave radiation to escape from the Earth, with consequent negative radiative forcing (term A). This beneficial effect of tree plantings is partly offset by the direct effects of decreasing albedo (i.e., less reflection), which means that more short-wave radiation is absorbed at the surface (term B). In addition, there are indirect effects of afforestation (terms C, D) because forests evaporate and transpire (termed evapotranspiration) more water than grasslands (e.g., Zhang et al. 2001; Beets and Oliver, 2007), principally because of higher interception of rainfall by forest canopies than shorter grassland canopies (Jarvis and McNaughton, 1986; Beets and Oliver, 2007).

The resultant surface radiation balance is complicated by the resultant changes in the partitioning of available energy into latent heat (evaporation of water) and sensible heat (terms $\mathrm{C}$ and D). Increasing latent heat flux reduces both the amount of energy available as sensible heat and the local surface temperature. That latent heat is released somewhere else in the atmosphere when water condenses again, but the increased amount of water vapour in the atmosphere absorbs 


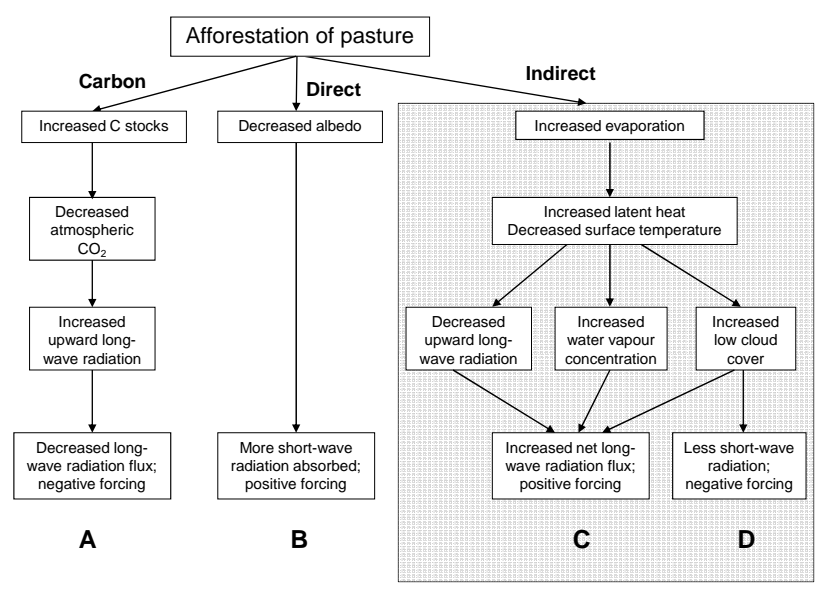

Fig. 1. Schematic representation of the direct $(\mathbf{A}, \mathbf{B})$ and indirect $(\mathbf{C}, \mathbf{D})$ radiative effects associated with conversion from pasture to forest. All the radiative fluxes described are at the surface and the convention is that fluxes are positive for energy moving towards the surface. Indirect effects are shown in the hatched box in this diagram because the present work considers only the carbon and direct albedo effects. Diagram modified from Findell et al. (2007).

some outgoing long-wave radiation, prevents it from escaping from the Earth system (term C) and adds to global warming. The increased amount of water transferred to the atmosphere must also be returned to the surface as precipitation, which involves cloud formation. As low clouds tend to have high albedo, they predominantly reduce the short-wave flux to the surface (term D) and thus cool the Earth.

In summary, the direct effect of decreasing albedo with afforestation (term B) will increase radiative forcing at the surface. However, increased evaporation (terms $\mathrm{C}$ and $\mathrm{D}$ ) can result in an increase or decrease in radiative forcing. The final combined effect is determined by the relative sizes of the two components (terms $\mathrm{C}$ and $\mathrm{D}$ ). If the combined net surface radiative balance is positive, then both latent and sensible heat fluxes may increase and surface temperatures may increase even more that that due to term $\mathrm{B}$ alone. These indirect effects are difficult to compute and were beyond the scope of the present study. However, other studies have shown that under some conditions they may be quantitatively as important as the direct effects (e.g., Bala et al., 2007).

Here, we provide an assessment of the impacts of changing albedo and carbon storage in trees on radiative forcing. Our focus is on land-use change from pasture to Pinus radiata forest at Puruki Forest, situated in New Zealand's Central North Island, where long-term measurements of forest growth and energy exchange are available. Our conclusion is based on comparison of these two opposing impacts on radiative forcing as the forest develops. A quantitative assessment of the indirect effects of changing land cover on radiative forcing from changes in the hydrological cycle for New Zealand requires regional-scale climate modelling and is beyond the scope of the work reported here. Unpublished regional climate modelling does suggest, however, that for New Zealand, afforestation is likely to lead to some increase in low cloud cover and cause a cooling to partly offset any warming from greater radiation absorption by forests (S. M. Dean, unpublished).

\section{Methods}

\subsection{Description of the Puruki site}

Puruki is a 34.4 ha catchment located in the Purukohukohu Experimental Catchment at the southern end of the Paeroa Range in the Central North Island of New Zealand (latitude $38^{\circ} 25^{\prime} 44^{\prime \prime} \mathrm{S}$, longitude $176^{\circ} 12^{\prime} 51^{\prime \prime} \mathrm{E}$ ). Originally used as pasture, Puruki was planted with $P$. radiata in 1973 at a nominal tree density of 2200 trees ha ${ }^{-1}$. Daily measurements of weather variables above the forest canopy began in 1976 at a mast installed in the Rua sub-catchment at Puruki, where early mortality reduced stocking to 1483 trees ha ${ }^{-1}$ by 1976 (Beets and Brownlie, 1987). In 1980, the forest stand was thinned to 550 trees ha ${ }^{-1}$ and the trees were pruned to $2 \mathrm{~m}$ height, with no further silvicultural operations undertaken thereafter. Following thinning, measurements ceased in 1982, and a new meteorological tower was installed about $30 \mathrm{~m}$ from the original mast, and measurements re-commenced from 1983.

Mean top height of the stand increased by approximately $1.5 \mathrm{~m} \mathrm{yr}^{-1}$ (Beets and Brownlie, 1987). Measurements of changes in tree biomass with forest development were available from Beets and Pollock (1987). These direct biomass measurements were supplemented with biomass predictions obtained using the C_Change model/300 Index growth model (Beets et al., 1999; Kimberley et al., 2005). These models utilise silvicultural information and ground data from inventory plots, which were installed in the Rua sub-catchment and measured over a full rotation. Stem volume per hectare was estimated from tree height and diameter measurements using generalised model corrections (Kimberley et al., 2005). Stand volume estimates were then converted to stand dry matter by multiplying wood volume by wood density. Expansion factors provided annual estimates of live-biomass carbon stocks over the length of the rotation. Dead biomass pools with their respective component decay rates were also included, which became particularly important following thinning. The same methods have been used for New Zealand's national planted forest carbon inventory (Beets et al., 2010).

In these calculations, we did not include soil carbon changes because detailed measurements at our experimental site had found no significant differences in soil carbon between pine and pasture soils (Beets et al., 2002). More generally, however, it is usually observed that soil carbon stocks are reduced following reforestation of pastures (Guo 
and Gifford, 2002). Differences tend to be more pronounced for conifer than broad-leaves species and increase with increasing rainfall (Guo and Gifford, 2002), which could be related to increased nitrogen leaching from sites with higher rainfall (Kirschbaum et al., 2008). Hence, while it was appropriate not to include soil carbon changes for our specific site, soil carbon changes should be included for generic analyses, or for other specific sites where changes in soil carbon might have been measured.

\subsection{Methods used to estimate albedo}

Incident and reflected short-wave radiation were measured using paired solarimeters (Solar Radiation Instruments SRI5) installed above the canopy at $35 \mathrm{~m}$ height. These instruments have a spectral response range across the full short-wave range from 250 to $3500 \mathrm{~nm}$. Data were recorded as hourly averages using a data logger (Campbell Scientific Inc., Model CR7). Values of albedo were calculated from the ratio of daily total reflected to incident short-wave radiation. Albedo measurements started in 1977, four years after stand establishment when leaf mass was about $4.2 \mathrm{t}$ dry matter $\mathrm{ha}^{-1}$ (Beets and Pollock, 1987) and were continued through to the end of 1992.

As the sequence of ground-based measurements at Puruki did not extend back to the time before forest establishment, pasture albedo was estimated from satellite measurements, using data from the MODIS satellite. Data were collected every eight days from 2000 to 2008. Pasture albedo was obtained from locations in close vicinity of the forest site.

These data were processed with a BRDF (Bidirectional Reflectance Distribution Function) to estimate albedo at the known sun angle throughout the year and with reflectance over the integral of all outgoing angles. Calculations were done with radiation received either by direct beam radiation from the sun at its known zenith angle or by diffuse radiation (Dymond et al., 2001). Daily albedo was weighted towards mid-day values based on estimated diurnally varying solar radiation. Total short-wave radiation albedo was calculated with the algorithm of Liang (2001).

To validate the procedure used for the present work, we used Landsat 4 imagery that was available at finer spatial resolution and at dates coincident with available ground observations. Four dates were selected with cloud-free conditions that allowed a direct comparison with ground-based measurements on the same days. Albedo was calculated for the pixel that corresponded to the location of the tower in the Puruki forest using atmospheric corrections and the BRDF information derived from analysis of the seasonal patterns in MODIS reflectance from similar pine forests.

\subsection{Calculations of radiative forcing}

\subsubsection{The radiative forcing of carbon storage}

The radiative forcing of an extra unit of carbon in the atmosphere can be calculated from first principles. The change in radiative forcing for a square metre of ground, $R_{\mathrm{m}}$ $\left(\mathrm{J} \mathrm{m}^{-2} \mathrm{~d}^{-1}\right)$ can be calculated as:

$\Delta R_{\mathrm{m}}=86400 \times 5.35 \times \ln (1+\Delta[\mathrm{C}] /[\mathrm{C}])$

where $[\mathrm{C}]$ is the background atmospheric carbon dioxide concentration, $\Delta[\mathrm{C}]$ is the change in atmospheric carbon dioxide concentration attributable to land-use change, and 86400 is the number of seconds in a day. The conversion " 5.35 " $\left(\mathrm{W} \mathrm{m}^{-2}\right)$ converts from units of carbon dioxide to radiative forcing (Harvey et al., 1997; Ramaswamy et al., 2001). This corresponds to radiative forcing of about $3.75 \mathrm{~W} \mathrm{~m}^{-2}$ for doubling carbon dioxide concentration, which is a mid-range climate sensitivity.

A change in carbon stocks, $\Delta \mathrm{C}(\mathrm{tC})$, needs to be converted to the corresponding concentration change in the atmosphere, $\Delta[\mathrm{C}]$, considering that $1 \mathrm{ppm}$ in carbon dioxide concentration corresponds to $2.123 \mathrm{GtC}$ (Joos et al., 1996) so that:

$\Delta[\mathrm{C}]=\Delta \mathrm{C} /\left(2.123 \times 10^{9}\right)$.

The total radiative forcing over a year and for the Earth as a whole, $\Delta R_{\mathrm{E}}$, can then be calculated as:

$\Delta R_{E}=\Delta R_{m} \times 510 \times 10^{12} \times 365$

where $510 \cdot 10^{12} \mathrm{~m}^{2}$ (or 510 million $\mathrm{km}^{2}$ ) is the surface area of the Earth, and 365 is the number of days in a year. With an atmospheric carbon dioxide concentration of $390 \mathrm{ppm}$, and for the Earth as a whole, the radiative forcing, $\Delta R_{\mathrm{E}}$, of the removal of 1 tonne carbon can be calculated as:

$$
\begin{aligned}
\Delta R_{\mathrm{E}} & =86400 \times 5.35 \times \ln \left(1+\frac{\Delta \mathrm{C} /\left(2.123 \times 10^{9}\right)}{390}\right) \\
& \times 510 \times 10^{12} \times 365=-104 \mathrm{GJ} \mathrm{tC}^{-1} \mathrm{yr}^{-1} .
\end{aligned}
$$

With carbon storage in trees, it is also necessary to consider possible carbon-cycle feedbacks. In essence, the carbon stored in trees lowers the atmospheric carbon dioxide concentration, which in turn reduces the carbon dioxide uptake by the natural global carbon pools, especially the oceans (Kirschbaum, 2003, 2006). The atmospheric carbon dioxide concentration is therefore reduced by less than the amount of carbon stored in trees, and the difference increases over the time of carbon storage. These are important considerations for the impact mitigation potential of biospheric carbon removal.

The calculations in the following analysis are done both with and without consideration of these carbon-cycle feedbacks, as either approach can be the most meaningful in its 
specific context. These processes are described in detail by Kirschbaum $(2003,2006)$, and that formulation is also used here.

\subsubsection{Radiative forcing due to albedo change}

The change in daily radiative forcing due to a change in albedo, $\Delta R_{\mathrm{d}}$, can be calculated as:

$\Delta R_{\mathrm{d}}=Q_{\mathrm{s}} \downarrow \times \Delta a \times\left(1-\alpha_{\mathrm{atm}}\right)$

where $Q_{\mathrm{s}} \downarrow$ is total daily downward solar radiation, $\Delta \mathrm{a}$ is the difference in albedo over the whole short-wave spectrum between two different land-use types and $\alpha_{\text {atm }}$ is the proportion of short-wave radiation absorbed by the atmosphere. We used an average global value for atmospheric absorption of $20 \%$ (Kiehl and Trenberth, 1997).

In principle, this calculation can be done at any scale, but for comparative purposes, scaling the numbers to a hectare is useful. Since radiation is usually given in units per square metre of ground area, a value of radiation needs to be converted to a hectare basis. Since radiation also follows a distinct seasonal cycle, it is necessary to sum these calculated values over at least a year. Hence, the difference in radiative forcing for a hectare over a year can be calculated as:

$\Delta R_{\mathrm{yr}}=\sum^{365} 10000 \times \Delta R_{\mathrm{d}}$

where 10000 is the number of square metres in a hectare, and 365 is the number of days in a year.

Calculated changes in albedo-based radiative forcing are a direct function of the average radiation received at specific locations and of the difference in albedo between two landuse types. This, in turn, is strongly affected by the extent of snow cover, when albedo changes between land-use types are most pronounced. In New Zealand, snow cover generally plays a role only in the higher alpine areas, but not in typical conifer-growing regions.

Average annual incoming radiation changes with latitude and with the extent of cloudiness. In New Zealand, annually averaged mean daily radiation ranges from about $11-12 \mathrm{MJ} \mathrm{m}^{-2} \mathrm{~d}^{-1}$ in the wet and cloudy parts of the far south of the South Island to about $15 \mathrm{MJ} \mathrm{m}^{-2} \mathrm{~d}^{-1}$ over most of the North Island (Leathwick et al., 2002). There is a distinct seasonal cycle, with minimum values in June (5$6 \mathrm{MJ} \mathrm{m}^{-2} \mathrm{~d}^{-1}$ ) and maximum values in December and January (c. $22 \mathrm{MJ} \mathrm{m}^{-2} \mathrm{~d}^{-1}$ ).

Using a mean annual incident solar radiation of $13.5 \mathrm{MJ} \mathrm{m}^{-2} \mathrm{~d}^{-1}$ and an albedo difference between two landuse types of $7 \%$ (i.e., albedo values of $13 \%$ for forest and $20 \%$ for pasture as observed in our study - see below), this translates into an annual radiative forcing, $\Delta R_{\mathrm{yr}}$, of:

$$
\begin{aligned}
\Delta R_{\mathrm{yr}} & =13.5 \times 0.07 \times(1-0.2) \times 10000 \times 365 \\
& =2759 \mathrm{GJ} \mathrm{ha}^{-1} \mathrm{yr}^{-1} .
\end{aligned}
$$

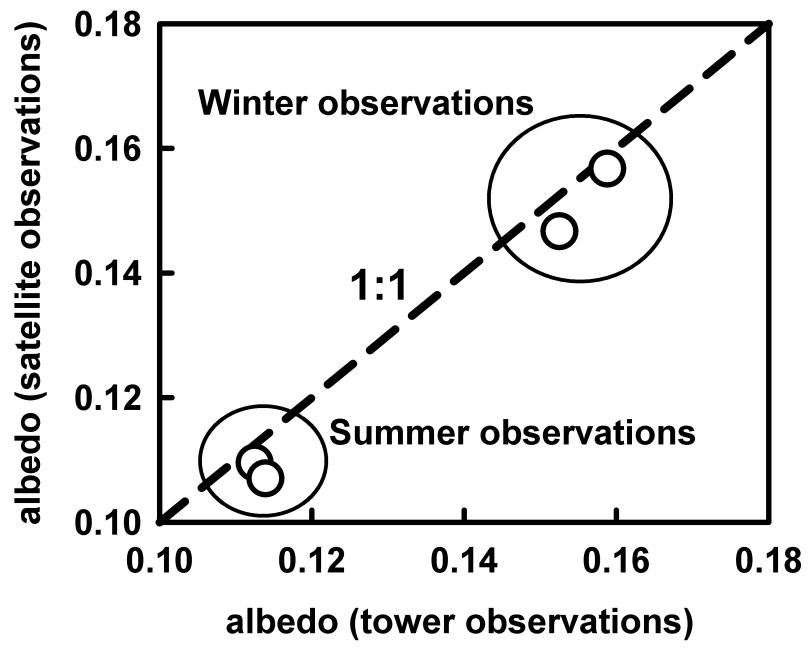

Fig. 2. Albedo measurements based on Landsat 4 satellite observations plotted against ground-based albedo measurements on matching days. Two measurements were obtained in summer and two in winter as indicated in the Figure. The dashed line is a 1:1 line.

For the specific calculations done here, we used the difference between daily measured albedo from our forest canopy and satellite derived measurements of pasture albedo for the same time of the year. Using Eqn. (7), the difference in albedo between pasture and forests was then multiplied by incoming radiation measured on respective days to calculate the radiative forcing effect for specific days. This ensured that seasonal variations in both albedo and incoming radiation were appropriately combined.

\section{Results}

Calculation of the radiative forcing of albedo changes critically depend on the magnitude of changes in albedo with land-use change. In our work, we had satellite derived estimates of pasture and forest albedo and ground-based measurements of the albedo of the developing forest at our test site. Within the respective observational periods, there were four dates with Landsat 4 data that allowed a direct comparison of satellite and ground-based albedo estimates. They consisted of two summer and two winter observations and thus allowed an assessment of both absolute values and the extent of seasonal variation (Fig. 2).

The comparisons between the two different methods gave comparable results for both summer and winter measurements, with just a slight difference by about $0.4 \%$ between satellite and ground-based measurements. This level of uncertainty is small relative to the size of the difference between land uses. It allowed us to use the satellite data with confidence in estimating the albedo of pasture sites in the vicinity of our forest site. 


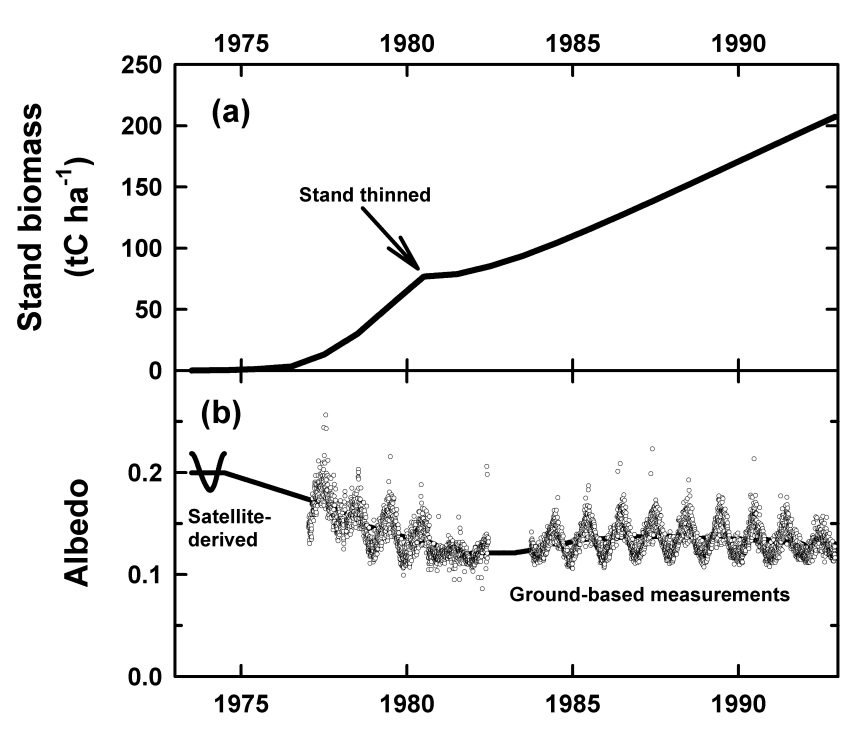

Fig. 3. Changes in stand biomass carbon (a) and albedo (b) measured at Puruki, and satellite-derived albedo estimates for pastures. Pasture albedo is plotted for 1973 (when the stand was established), but actual measurements correspond to the mean of observations from 2000 to 2008. Also shown are 365-day running means of forest albedo, and a linear interpolation from the pasture data at the end of 1973 to the beginning of the trend line for the forest data. Biomass data include estimated carbon stocks in litter and roots.

Comparing the radiative forcing of the removal of $1 \mathrm{tC}$ of $-104 \mathrm{GJ} \mathrm{tC}^{-1} \mathrm{yr}^{-1}$ (Eqn. 6) with that of a $7 \%$ albedo change (2759 GJ ha ${ }^{-1} \mathrm{yr}^{-1}$, Eqn. 9), it became possible to calculate the required amount of carbon storage needed, $B$, to balance the increase in albedo from increased radiation absorption as:

$B=\Delta R_{\mathrm{yr}} / \Delta R_{\mathrm{E}}=2759 /-104=-26.5 \mathrm{tCha}^{-1}$.

Hence, forests in New Zealand need to remove about $25 \mathrm{tC} \mathrm{ha}^{-1}$ before the radiative cooling effect of carbon storage outweighs the warming effect of increased absorption of short-wave radiation. At Puruki, it took about 4.5 years before the stand had accumulated $25 \mathrm{tC} \mathrm{ha}^{-1}$ (Fig. 3a). Growth and carbon accumulation was slow for the first few years as trees were still expanding their crowns and increased their ability to intercept and utilise most incoming radiation.

Thereafter, growth in stand carbon stocks proceeded more rapidly before reaching a temporary halt as the stand was thinned. Thinnings at Puruki were not removed from the site so that carbon stocks did not decrease, but for a few years after thinning, there was no increase in carbon stocks as the decay of dead stems on the forest floor and decaying coarse roots balanced the on-going carbon accretion in the remaining, and vigorously growing, trees.

Measured albedo at the Puruki site (Fig. 3b) followed a distinct seasonal cycle due to the changing angle of the sun, which changed the proportion of incident radiation being absorbed or reflected. In winter, with a more oblique sun angle, a slightly higher proportion of incident radiation was reflected (Fig. 2). Albedo also changed greatly with stand development from a typical albedo for pasture of about $20 \%$ (based on satellite observations) to about $12-13 \%$ when the forest was 8 years old (Fig. 3b).

These differences in albedo (Fig. 3b), together with observation of stand-carbon storage over time (Fig. 3a), were used to calculate changes in radiative forcing of the two components (Fig. 4). Albedo forcing displayed a strong seasonal cycle, primarily due to seasonal changes in incident solar radiation which was slightly increased further by the seasonally changing albedo (Fig. 3b), with highest values over the winter months (Fig. 2). Numbers were positive, indicating that the change in albedo from pasture to forest constituted positive radiative forcing, with a warming effect.

Carbon-based radiative forcing followed the changes in carbon stored in the forest. Initially after tree planting, there was a lag for the first few years as trees slowly established themselves at the site, followed by a decrease that was temporarily halted in 1980 when the stand was thinned, and then a sustained growth period thereafter. Overall, carbon-based radiative forcing was negative, with a cooling effect.

Consideration of the feedback effects via adjustments in the carbon pools in the global carbon cycle reduced the overall beneficial effect of carbon storage. In essence, carbon removal from the atmosphere and its storage in trees reduces the inherent carbon uptake by natural carbon pools especially the oceans (Kirschbaum, 2003, 2006). The atmospheric carbon dioxide concentration is therefore reduced by less than the amount of carbon stored in a stand of trees. As that carbon uptake takes time, especially uptake by the less accessible pools like the deep oceans, the feedback effect becomes stronger over time, and the difference between calculated benefits with and without carbon cycle feedbacks widens. By the end of the rotation, the carbon cycle feedback reduced the beneficial effect of carbon storage in trees by about one third (Fig. 4).

The magnitude of radiative forcing from albedo changes and carbon storage were comparable for the first few years after stand establishment, but stand biomass continued to increase long after albedo changes had reached their maximum so that the carbon storage effect dominated for older stands (Fig. 5). The difference was less pronounced if carbon-cycle feedbacks were included. In that case, the on-going increase in stand-level carbon storage led to progressively less global benefit because stand-level storage was increasingly offset by adjustments in other carbon pools.

These calculations gave an offset of the carbon storage benefit through albedo changes by the end of the rotation by an average of $10 \%$ if the carbon stored in the forest was considered alone (Fig. 5c) and $15 \%$ if carbon storage by the carbon cycle feed-backs was included (Fig. 5d). Integrated over the whole length of the rotation, the offset was $17 \%$ if only carbon storage in the forest was considered and $24 \%$ if carbon-cycle feedbacks were included. 


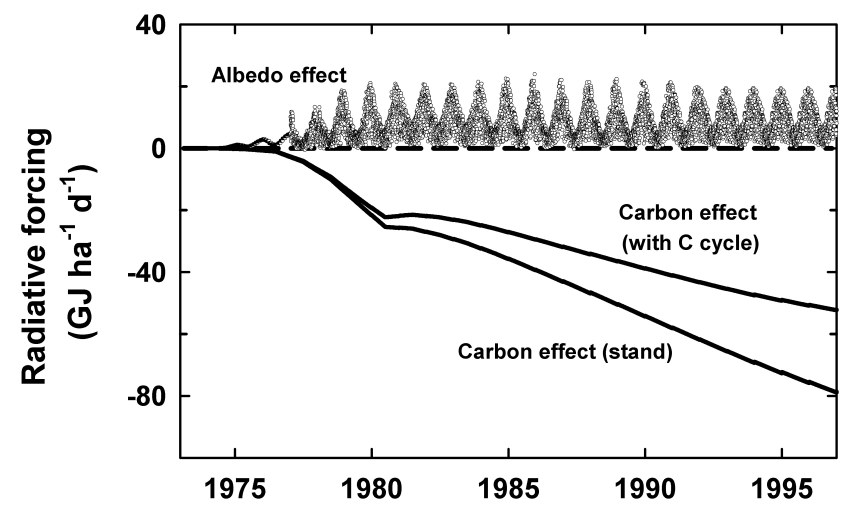

Fig. 4. Calculated radiative forcing due to changes in albedo and carbon storage. Albedo-based forcing is calculated daily from observed albedo and incident solar radiation. Carbon dioxide is distributed globally so that there are no daily variations. Carbon-based calculations were done with considering stand-level carbon storage only (stand), and after calculating carbon cycle feedback effects (with C cycle). The stand was thinned in 1980, which accounts for the discontinuity in the slope of the lines depicting carbon-based radiative forcing.

\section{Discussion}

The detailed measurements available from Puruki allowed quantification of the offset of the carbon storage benefit by albedo changes that accompanied land-use change from pasture to exotic forest. Carbon storage in forests had the net effect of lowering the atmospheric carbon dioxide concentration and through that, total radiative forcing, but the decrease in albedo resulted in the absorption of more short-wave radiation, with positive radiative forcing. These two effects were of comparable magnitude in young stands, but in older stands, the carbon-storage effect became much greater than the albedo effect. Under New Zealand conditions, it could therefore be concluded that the albedo changes negated the benefit from carbon storage over a rotation of a conifer forest by $17-24 \%$, depending on the inclusion or omission of the consideration of carbon-cycle feedbacks

These values are smaller than those calculated by Betts (2000) and Bala et al. (2006) for calculations at higher latitude, with the key differences being the extent of snow cover and the projected forest growth rates in respective regions. Betts (2000), for example, used a $5 \%$ difference in albedo between forested and non-forested land under snow-free conditions, which was less than the $7 \%$ difference found at $\mathrm{Pu}$ ruki. However, the values used by Betts (2000) increased to an albedo difference of up to $55 \%$ with snow present $(25 \%$ for snow covered forest and $80 \%$ for snow-covered open land).

Betts (2000) also assumed carbon storage potentials between about $100 \mathrm{tC} \mathrm{ha}^{-1}$ for cold or dry regions in Siberia, Canada or China and $200 \mathrm{tCha}^{-1}$ in more temperature

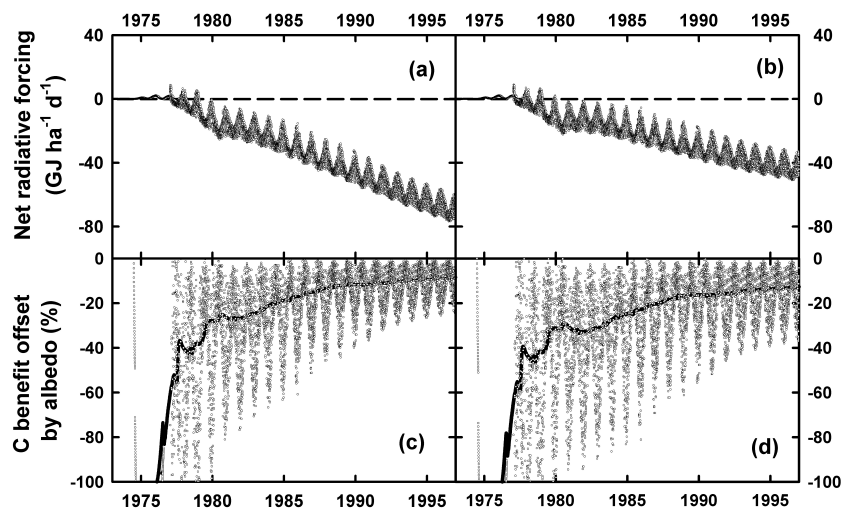

Fig. 5. Net radiative forcing effect combining albedo and carbonstorage effects. Calculations were done for either stand-level carbon storage (panels a, c) or with inclusion of carbon cycle feed-backs (panels b, d) and are expressed as either net radiative forcing per hectare (panels $a, b$ ) or as a percentage offset on the carbon storage benefit by the associated albedo changes (panels c, d).

regions of Europe and North America. The Puruki stand reached carbon storage of $100 \mathrm{tC} \mathrm{ha}^{-1}$ after about 10 years and $200 \mathrm{tC} \mathrm{ha}^{-1}$ after 20 years (Fig. 3). Hence, the differences in snow cover and biological growth potential between global regions accounts for the difference in the net balance between carbon storage and direct albedo effects. Under New Zealand conditions, the radiative forcing changes resulting from albedo changes therefore only diminish but do not negate the climate-change benefit from tree plantings.

The exact magnitude of the offset depended on a number of factors, most importantly, on the difference in albedo between the different land-cover types. We confirmed that satellite and ground-based measurements agreed well at our forest site. Using the same algorithms for deriving pasture albedo from single reflectance measures during a satellite overpass, we could derive the matching albedo of pastures in the vicinity of our measured forest.

Breuer et al. (2003) summarised albedo values from different authors and found albedos for coniferous forests to be generally between 11-14\% and grassland albedo between 19-27\%. Hollinger et al. (2010) similarly reported grassland albedos of $18-21 \%$ and $11 \%$ for evergreen needle-leaf forests in temperate locations. Our measured values for New Zealand pastures were generally at the low range of global observations, probably owing to the general good growing condition of most New Zealand pastures, with few times of grass drying off or developing bare patches due to moisture limitations or excess grazing. There are also no periods of extended snow cover, especially not in the vicinity of our forest site with the typical mild weather of New Zealand's North Island.

Albedo of forests also changes with age (Fig. 3b). Amiro et al. (2006) observed albedo to decrease with increasing forest age, whereas our observations indicate lowest albedo at 
about 10 years of age, but a slight increase for older stands which coincided with thinning, which may be the directly responsible factor. These albedo changes are only slight but significant nonetheless as even a $1 \%$ difference in albedo can translate into a significant difference in radiative forcing.

The magnitude of the albedo offset also depends on whether the effect was integrated over the whole life of a rotation, or was calculated only at the end of the rotation. The offset was obviously greater when it included the early stages of stand establishment when both effects were of comparable magnitude. For longer rotation lengths, the contribution of later growth stages became progressively more important as the carbon storage effect became greater than the albedo effect.

The offset percentage was also different for calculations done with or without consideration of carbon cycle feedbacks. Whether those carbon cycle feedbacks should be included depends on the context within which specific questions are being asked. Calculations of stand-level carbon changes give the relevant net radiative forcing change attributable to a particular forest. However, perturbation of the global carbon budget by forests leads to a change in the global carbon cycling that partly negates the initial standlevel change in carbon storage. So, to calculate the net effect of a land-use change, it is relevant to include the net effect of planting forest with its consequent adjustments in natural carbon pools.

For a comparison of forest planting and fossil-fuel management, the same carbon-cycle feedbacks apply to both. The emission of 1 tonne of carbon from fossil fuels leads to an increase in atmospheric carbon content by less than 1 tonne because some of that carbon will be absorbed by the oceans. To calculate the benefit of saving the emission of 1 tonne of fossil fuels against the benefit of storing 1 tonne of carbon in the biosphere, the comparison therefore needs to be consistent in either including or excluding carbon cycle feedbacks in both instances. As these feedbacks are not generally included in calculating the effect of fossil-fuel management, it would be appropriate to base comparison on stand-level calculations.

In the present work, we were not able to quantify the indirect effects of afforestation resulting from changes in the temperature profile between the surface and the atmosphere, and those resulting from increased evapotranspiration from forest canopies and consequently increased cloud formation. Previous work (e.g., Bala et al., 2007) has indicated that the indirect effect can be of a similar magnitude (and opposite sign) as the direct, ground-based albedo changes, especially in more tropical locations. For New Zealand, we cannot currently quantify whether, or to what extent, indirect effects may negate the direct albedo effect on radiative forcing.

\section{Conclusions}

The case study presented here dealt with the direct albedo changes and the associated change in the absorption of shortwave solar radiation. This was compared against the global effect of reductions in atmospheric carbon dioxide concentration due to increased carbon storage. Our calculations showed that under New Zealand conditions, plantation establishment had a significant overall net cooling effect. While albedo changes reduced the overall tree-planting benefit, carbon storage was of greater quantitative importance. This finding contrasts with the findings for boreal regions where albedo changes can be quantitatively more important than carbon storage, giving a net warming effect of tree plantations (Betts, 2000).

The main difference between the findings for different regions relates to the role of snow, which can greatly accentuate differences in albedo between vegetation types (Betts, 2000). Snow plays an important role in the boreal zone, but only a minor one in New Zealand's conifer-growing regions. The growth rate of trees and their carbon-storage potential is also much greater in New Zealand than in more slowly growing boreal forests. That shifts the relative benefit in favour of tree plantings. On the other hand, annual incident solar radiation is also greater in New Zealand than in the boreal zone so that the same albedo difference caused greater radiative forcing in New Zealand than in regions receiving less short-wave radiation.

However, irrespective of the quantitative importance of albedo in specific regions and circumstance, our study, like previous ones (e.g., Brovkin et al., 1999; Betts, 2000; Bala et al., 2007, 2007; Pongratz et al., 2011), has shown that albedo changes can be important enough to be considered in an overall assessment of the radiative forcing consequences of a change in land use (Schwaiger and Bird, 2010; South et al., 2011) and for urban design (Akbari et al., 2009). Climate change cannot be mitigated efficiently if management response strategies consider only some radiatively important factors (i.e., carbon storage) while ignoring others (i.e., direct effects on the Earth's energy balance). Optimal management of the Earth's biosphere for climate-change mitigation can only be achieved if all relevant factors are considered, quantified and included in an overall assessment.

Acknowledgements. This work was supported by the New Zealand Ministry of Agriculture and Forestry. We would like to thank Anne Austin, Kailash Thakur and several reviewers from the Ministry of Agriculture and Forestry for many useful comments on the manuscript.

Edited by: G. Wohlfahrt 


\section{References}

Akbari, H., Menon, S., and Rosenfeld, A.: Global cooling: increasing world-wide urban albedos to offset $\mathrm{CO}_{2}$, Climatic Change, 95, 275-286, 2009.

Amiro, B. D., Orchansky, A. L., Barr, A. G., Black, T. A., Chambers, S. D., Chapin, F. S., Goulden, M. L., Litvakg, M., Liu, H. P., McCaughey, J. H., McMillan, A., and Randerson, J. T.: The effect of post-fire stand age on the boreal forest energy balance, Agr. Forest Meteorol., 140, 41-50, 2006.

Bala, G., Caldeira, K., Mirin, A., Wickett, M., and Delire, C.: Biogeophysical effects of $\mathrm{CO}_{2}$ fertilization on global climate, Tellus, 58B, 620-627, 2006.

Bala, G., Caldeira, K., Wickett, M., Phillips, T. J., Lobell, D. B., Delire, C., and Mirin, A.: Combined climate and carbon-cycle effects of large-scale deforestation, P. Natl. Acad. Sci. USA, 104, 6550-6555, 2007.

Beets, P. N. and Brownlie, R. K.: Puruki experimental catchment: Site, climate, forest management, and research, New Zeal. J. For. Sci., 17, 173-180, 1987.

Beets, P. N. and Pollock, D. S.: Accumulation and partitioning of dry matter in Pinus radiata as related to stand age and thinning, New Zeal. J. For. Sci., 17, 246-271, 1987.

Beets, P. N. and Oliver, G. R.: Water use by managed stands of Pinus radiata, indigenous podocarp/hardwood forest, and improved pasture in the Central North Island of New Zealand, New Zeal. J. For. Sci., 37, 306-323, 2007.

Beets, P. N., Robertson, K. A., Ford-Robertson, J. B., Gordon, J., and Maclaren, J. P.: Description and validation of C_Change: a model for simulating carbon content in managed Pinus radiata stands, New Zeal. J. For. Sci., 29, 409-427, 1999.

Beets, P. N., Oliver, G. R., and Clinton, P. W.: Soil carbon protection in podocarp/hardwood forest, and effects of conversion to pasture and exotic pine forest, Environ. Pollut., 116, S63-S73, 2002.

Beets, P. N., Brandon, A., Fraser, B. V., Goulding, C. J., Lane, P. M., and Stephens, P. R.: National Forest Inventories reports: New Zealand, in: National Forest Inventories - Pathways for Common Reporting, edited by: Tomppo, E., Gschwantner, Th., Lawrence, M., and McRoberts, R. E., Springer Verlag, ISBN 978-90-4813232-4, 391-410, 2010.

Betts, R. A.: Offset of the potential carbon sink from boreal forestation by decreases in surface albedo, Nature, 408, 187-190, 2000.

Betts, R. A., Falloon, P. D., Goldewijk, K. K., and Ramankutty, N.: Biogeophysical effects of land use on climate: Model simulations of radiative forcing and large-scale temperature change, Agr. Forest Meteorol., 142, 216-233, 2007.

Breuer, L., Eckhardt, K., and Frede, H. G.: Plant parameter values for models in temperate climates, Ecol. Model., 169, 237-293, 2003.

Brovkin, V., Ganopolski, A., Claussen, M., Kubatzki, C., and Petoukhov, V.: Modelling climate response to historical land cover change, Global Ecol. Biogeogr., 8, 509-517, 1999.

Davin, E. L., de Noblet-Ducoudre, N., and Friedlingstein, P.: Impact of land cover change on surface climate: Relevance of the radiative forcing concept, Geophys. Res. Lett. 34, L13702, doi:10.1029/2007GL029678, 2007.

Dymond, J. R., Shepherd, J. D., and Qi, J.: A simple physical model of vegetation reflectance for standardising optical satellite imagery, Remote Sens. Environ., 77, 230-239, 2001.
Findell, K. L., Shevliakova, E., Milly, P. C. D., and Stouffer, R. J.: Modeled impact of anthropogenic land cover change on climate, J. Climate, 20, 3621-3634, 2007.

Forster, P., Ramaswamy, V., Artaxo, P., Berntsen, T., Betts, R., Fahey, D. W., Haywood, J., Lean, J., Lowe, D. C., Myhre, G., Nganga, J., Prinn, R., Raga, G., Schulz, M., and Van Dorland, R.: Changes in Atmospheric Constituents and in Radiative Forcing, in: Climate Change 2007: The Physical Science Basis, Contribution of Working Group I to the Fourth Assessment Report of the Intergovernmental Panel on Climate Change, edited by: Solomon, S., Qin, D., Manning, M., Chen, Z., Marquis, M., Averyt, K. B., Tignor, M., and Miller, H. L., Cambridge University Press, Cambridge, United Kingdom and New York, NY, USA, 129-234, 2007.

Guo, L. B. and Gifford, R. M.: Soil carbon stocks and land use change: a meta analysis, Global Change Biol., 8, 345-360, 2002.

Harvey, L. D. D., Gregory, J., Hoffert, M., Jain, A., Lal, M., Leemans, R., Raper, S., Wigley, T., and de Wolde, J.: An introduction to simple climate models used in the IPCC Second Assessment Report, Intergovernmental Panel on Climate Change, Technical Paper II, 50 pp., 1997.

Hollinger, D. Y., Ollinger, S. V., Richardson, A. D., Meyers, T. P., Dail, D. B., Martin, M. E., Scott, N. A., Arkebauer, T. J., Baldocchi, D. D., Clark, K. L., Curtis, P. S., Davis, K. J., Desai, A. R., Dragoni, D., Goulden, M. L., Gu, L., Katul, G. G., Pallardy, S. G., Paw, U. K. T., Schmid, H. P., Stoy, P. C., Suyker, A. E., and Verma, S. B.: Albedo estimates for land surface models and support for a new paradigm based on foliage nitrogen concentration, Global Change Biol., 16, 696-710, 2010.

Jarvis, P. G. and McNaughton, K. G.: Stomatal control of transpiration: scaling up from leaf to region, Adv. Ecol. Res., 15, 1-19, 1986.

Jarvis, P. G., James, G. B., and Landsberg, J. J.: Coniferous forest, in: Vegetation and the Atmosphere, Volume 2, edited by: Monteith, J. L., Academic Press, London, 171-240, 1976.

Joos, F., Bruno, M., Fink, R., Siegenthaler, U., Stocker, T. F., Le Quere, C., and Sarmiento, J. L.: An efficient and accurate representation of complex oceanic and biospheric models of anthropogenic carbon uptake, Tellus, 48B, 397-417, 1996.

Juang, J.-Y., Katul, G., Siqueira, M., Stoy, P., and Novick, K.: Separating the effects of albedo from eco-physiological changes on surface temperature along a successional chronosequence in the southeastern United States, Geophys. Res. Lett., 34, L21408, doi:10.1029/2007GL031296, 2007.

Kiehl, J. T. and Trenberth, K. E.: Earth's annual global mean energy budget, Bull. Am. Met. Soc., 78, 197-208, 1997.

Kimberley, M. O., West, G. G., Dean, M. G., and Knowles, L. R.: The 300 Index - a volume productivity index for radiata pine, New Zeal. J. For. Sci., 50, 13-18, 2005.

Kirschbaum, M. U. F.: Can trees buy time? An assessment of the role of vegetation sinks as part of the global carbon cycle, Climatic Change, 58, 47-71, 2003.

Kirschbaum, M. U. F.: Temporary carbon sequestration cannot prevent climate change, Mitig. Adapt. Strateg. Glob. Change, 11, 1151-1164, 2006.

Kirschbaum, M. U. F., Guo, L. B., and Gifford, R. M.: Observed and modelled soil carbon and nitrogen changes after planting a Pinus radiata stand onto former pasture, Soil Biol. Biochem., 40, 247-257, 2008. 
Landsberg, J. J. and Gower, S. T.: Applications of Physiological Ecology to Forest Management, Academic Press, San Diego, 354 pp., 1997.

Leathwick, J. R., Wilson, G., and Stephens, R. T. T.: Climate Surfaces for New Zealand, Landcare Research Contract Report: LC9798/126, Landcare Research, 26 pp., available at: http://www.landcareresearch.co.nz/databases/lenz/ downloads/Climate_Surfaces_for_New_Zealand_revised.pdf, last accessed: 7 March 2011, 2002.

Liang, S.: Narrowband to broadband conversions of land surface albedo, I. Algorithms. Remote Sens. Environ., 76, 213-238, 2000.

Montenegro, A., Eby, M., Mu, Q. Z., Mulligan, M., Weaver, A. J., Wiebe, E. C., and Zhao, M. S.: The net carbon drawdown of small scale afforestation from satellite observations, Global Planet. Change, 69, 195-204, 2009.

Pongratz, J., Reick, C. H., Raddatz, T., Caldeira, K., and Claussen, M.: Past land use decisions have increased mitigation potential of reforestation, Geophys. Res. Lett., 38, L15701, doi:10.1029/2007GL031296, 2011.

Ramaswamy, V., Boucher, O., Haigh, J. D., Hauglustaine, D., Haywood, J., Myhre, G., Nakajima, T., Shi, G. Y., and Solomon, S.: Radiative Forcing of Climate Change, in: Climate Change 2001: The Scientific Basis. Contribution of Working Group I to the Third Assessment Report of the Intergovernmental Panel on Climate Change, edited by: Houghton, J. T., Ding, Y., Griggs, D. J., Noguer, M., van der Linden, P. J., Dai, X., Maskell, K., and Johnson, C. A., Cambridge University Press, Cambridge, UK and New York, NY, USA, 349-416, 2001.
Schwaiger, H. P. and Bird, D. N.: Integration of albedo effects caused by land use change into the climate balance: Should we still account in greenhouse gas units? Forest Ecol. Manage., 260, 278-286, 2010.

Shi, Z., Yan, X., Yin, C., and Wang, Z.: Effects on historical land cover changes on climate, Chinese Sci. Bull., 52, 2575-2583, 2007.

South, D. B., Lee, X., and Messina, M. G.: Will afforestation in temperate zones warm the Earth? J. Hort. For., 3, 195-199, 2011.

Zhang, L., Dawes, W. R., and Walker, G. R.: Response of mean annual evapotranspiration to vegetation changes at catchment scale, Water Resour. Res., 37, 701-708, 2001.

Zhang, J. and Walsh, J. E.: Thermodynamic and hydrological impacts of increasing greenness in northern high latitudes. J. Hydrometeorol., 7, 1147-1163, 2006.

Zhang, J. and Walsh, J. E.: Relative impacts of vegetation coverage and leaf area index on climate change in a greener north, Geophys. Res. Lett., 34, L15703, doi:10.1029/2007GL030852, 2007. 